\title{
СТИМУЛИРОВАНИЕ ИНВЕСТИЦИОННОЙ АКТИВНОСТИ КАК ФАКТОР ПОВЫШЕНИЯ ЭКОНОМИЧЕСКОЙ БЕЗОПАСНОСТИ ТЕРРИТОРИАЛЬНО-ОТРАСЛЕВОГО КОМПЛЕКСА
}

Повышение уровня экономической безопасности промыиленного комплекса требует стимулирования инвестиционной активности в отраслях, где длительный инвестиционный цикл и маситабность реализуемых проектов выступают естественными ограничителями, для преодоления которьх необходимо использование механизма государственно-частного партнерства. $B$ статье предложена модель поиска оптимальной схемы отбора и финансирования инвестиционных проектов с учетом факторов, влияюиих на уровень экономической безопасности мезоуровневых систем. Результаты исследования показали, что в случае, когда доля инфраструктурных инвестиций превынает $50 \%$, участие государства в реализации проекта в рамках государственно-частного партнерства нецелесообразно, так как точка равновесия отсутствует, а интервал равновесных значений индексов бюджетной и финансовой эффективности превынает установленные границы.

Ключевые слова: экономическая безопасность, промылленность, инвестиции, государственно-частное партнерство.

\section{Vladimir Rudenko, Petr Shirov STIMULATION OF INVESTMENT ACTIVITY AS FACTOR OF INCREASE IN ECONOMIC SECURITY \\ OF THE TERRITORIAL AND BRANCH COMPLEX}

Increasing the level of economic security of the industrial complex requires the stimulation of investment activity in industries where the long investment cycle and the scale of projects are natural constraints to overcome which it is necessary to use the mechanism of public-private partnership. In the article the model of search of the optimum scheme of selection and financing of investment projects taking into account the factors influencing the level of economic security of meso-level systems is offered. The results of the study showed that in the case where the share of infrastructure investment exceeds $50 \%$ of the state's participation in the implementation of the project within the framework of public-private partnership is impractical, since there is no equilibrium point, and the interval of equilibrium values of the indices of budgetary and financial efficiency exceeds the established boundaries.

Key words: economic security, industry, investment, public-private partnership.

Bведение / Introduction. Обеспечение экономической безопасности национальной промышленности в последнее время привлекает все больше внимания в силу исчерпания потенциала инерционного роста территориально-отраслевых комплексов и активизации поиска внутренних источников ее развития в долгосрочной перспективе. Ключевая роль в решении этой проблемы отводится стимулированию инвестиционной активности хозяйствующих субъектов в направлении модернизации производственной базы отраслей промышленности и повышению уровня ее конкурентоспособности. Как отмечают С. И. Борталевич и А. В. Акопова, для качественного осуществления новой индустриализации экономической системы страны, которая включит не только создание передовых высокотехнологических секторов, но и инновационное развитие базовых отраслей, востребованы значительные трансформации в инвестиционном климате, технико-технологических подходах, действующих организационных моделях [1]. 
Инвестиционная составляющая экономической безопасности есть характеристика мезоуровневой системы и один из показателей устойчивого социально-экономического развития региона, формирующий базу как в материальном производстве, так и сфере услуг повышения экономической безопасности. С этой позиции инвестиционный потенциал промышленного комплекса представляет собой интегральный показатель, включающий ресурсно-сырьевую, инновационную, инфраструктурную, финансовую, производственную, а также трудовую составляющие.

Рассматривая повышение уровня экономической безопасности на основе стимулирования инвестиционной активности отраслей промышленности как процесс, необходимо структурировать и формализовать управляющие воздействия, направленные на достижение поставленных целей [4]. В этом случае предметом моделирования будут инвестиционные процессы, протекающие в промышленности, а объектом - отдельные территориально-отраслевые комплексы. Тогда моделирование процесса инвестиционного развития в контексте обеспечения экономической безопасности будет включать следующие этапы:

- детерминирование ключевых целей и задач обеспечения экономической безопасности;

- определение механизмов и подходов по стимулированию инвестиционной активности хозяйствующих субъектов в промышленном комплексе;

- определение конкретных условий и инструментов достижения поставленных целей;

- $\quad$ критериальная формализация процессов обеспечения экономической безопасности за счет активизации инвестиционного развития отраслей промышленности

Выбор отраслевого уровня для моделирования объясняется тем, что в мезоуровневых системах максимально проявляется синергетический эффект обеспечения экономической безопасности при реализации крупномасштабных инвестиционных проектов. Также необходимо учитывать, что целенаправленное стимулирование инвестиционной активности со стороны органов государственной власти обеспечивает максимальный уровень управляемости и дает возможность повысить качество инвестиционных процессов в мезоуровневых системах. Это предполагает необходимость трансформации действующей системы институтов в сторону активизации использовании экономических инструментов, снижения давления контролирующих органов на бизнес, что будет способствовать росту инвестиций в территориально-отраслевых комплексах и достижению приемлемого уровня экономической безопасности.

Maтериалы и методы / Materials and methods. Одним из эффективных инструментов стимулирования инвестиционной активности в мезоуровневых системах можно считать практику реализации инфраструктурных проектов с использованием государственно-частного партнерства (ГЧП) [7]. По нашему мнению, государственная поддержка реализации крупномасштабных инвестиционных проектов в современных условиях экономической стагнации российской экономики является необходимым и весьма эффективным направлением модернизации отраслей промышленности и повышения экономической безопасности за счет минимизации рисков потенциальных инвесторов. Особенно актуально предоставление государственных гарантий при реализации таких проектов и субсидирование части затрат в отношении инфраструктурного обеспечения, а также снижение уровня налоговой нагрузки для предприятий промышленности. Реализация инвестиционных проектов в рамках ГЧП позволяет снизить не только инфраструктурные риски, но и способствует формированию селективной политики распределения имеющихся бюджетных средств, что особенно актуально в условиях ограниченного их объема. Как отмечает В. Г. Варнавский, минимизация инвестиционных рисков достигается за счет «обмена части финансирования инфраструктурной части проекта на предоставление мер поддержки» [2].

При этом следует учитывать ряд законодательных и экономических ограничений использования инструментов ГЧП [8]:

- одномоментно снижается нагрузка на бюджеты субъектов РФ, несмотря на выделение бюджетных средств на реализацию приоритетных инвестиционных проектов; 
- по своей экономической сути налоговые льготы являются выпадающими доходами бюджетной системы, что связано с недополучением части налоговых поступлений, хотя и равномерно распределенной на период их предоставления (максимальный срок до 5 лет);

- $\quad$ размер субсидирования процентной ставки ограничен объемом заемных средств инвестора, а также связан с ключевой ставкой ЦБ РФ (не должен превышать $2 / 3$ ставки рефинансирования);

- остаются риски неисполнения обязательств со стороны частного инвестора.

Для оценки целесообразности использования механизма ГЧП в процессе обеспечения экономической безопасности территориально-отраслевого комплекса нами был проанализирован ряд крупномасштабных инвестиционных проектов, планируемых к реализации на территории Северо-Кавказского федерального округа. В качестве целевых ориентиров были приняты их бюджетная и финансовая эффективность. Итоговый отбор проектов, реализация которых возможна в рамках ГЧП, был проведен на базе данных Министерства экономического развития РФ, где представлены проекты, софинансируемые за счет средств Инвестиционного фонда РФ [5]. В итоге были выбраны проекты, планируемые к реализации в субъектах СКФО, в которых осуществляются типовые меры государственной поддержки инвестиционных проектов.

1. Кабардино-Балкарская Республика - «Создание завода по производству полиэтилентерефтала пищевого и текстильного назначения мощностью 486 тыс. тонн в год».

2. Республика Дагестан - «Строительство стеклотарного завода „Анжи-Стекло”». Инфраструктурное обеспечение проекта связано со строительством объектов транспортной, коммунальной и энергетической инфраструктуры.

3. Республика Дагестан - «Строительство завода по производству гипса и гипсосодержащих строительных материалов в промышленной зоне с. Кафыр-Кумух».

4. Республика Ингушетия - «Строительство инфраструктуры кластера по добыче стекольного сырья для производства стеклянной тары в Республике Ингушетия).

5. Ставропольский край - «Металлургический завод „СтавСталь” (1-я очередь). Комплекс прокатного цеха».

6. Ставропольский край - «Строительство завода по производству сэндвич-панелей и вентиляционных изделий». Инфраструктурное обеспечение проекта связано со строительством наружных сетей электроснабжения, газоснабжения, водоотведения, водопровода.

7. Ставропольский край - «Создание комплекса по переработке газа Северного Каспия в этилен, полиэтилен и полипропилен (1-я очередь)».

Экзогенными факторами модели являются переменные, учитываемые в стандартной финансовой модели оценки эффективности реализации инвестиционного проекта [9], а также его исходные технико-экономические характеристики. При этом в базовой модели строительство объекта промышленного производства осуществляется полностью за счет средств частного инвестора, а государственная поддержка заключается в инфраструктурном обеспечении за счет средств инвестиционного фонда РФ и средств региональных бюджетов, при этом предоставление субсидий и налоговых льгот не рассматривается.

В качестве эндогенных переменных выступают показатели, которые позволяют оценить целесообразность реализации инвестиционного проекта в случае выбора стратегии в рамках ГЧП.

Базовым ориентиром является критерий, который в литературе получил название «равновесная эффективность инвестиционного проекта) [6]. В данном случае равновесное состояние представляет собой оптимальный уровень, достижение которого гарантирует достижение баланса интересов государства и бизнеса как основных участников инвестиционного проекта, реализуемого в рамках ГЧП. В соответствии с этим использование такого показателя позволяет отобрать 
оптимальный вариант выполнения проекта с заранее определенными технико-экономическими характеристиками, которые лежат в заданном диапазоне по финансовой, социальной и бюджетной эффективности.

Под бюджетной эффективностью понимаются публичные экономические выгоды, которые представляют собой прежде всего дополнительные налоговые поступления в региональный бюджет [3]. Оценка финансовой эффективности интересует в основном частных инвесторов, для чего используется утвержденная приказом Министерства экономического развития РФ от 30.11 .2015 № 894 «Методика оценки эффективности проекта государственно-частного партнерства и определения их сравнительного преимущества» [10]

В качестве параметров экономико-математической модели отметим следующие

- налоговые льготы учитываются в модели как поправочный коэффициент который составляет $15 \%$;

- $\quad$ максимальный объем предоставляемых субсидий зависит от величины предоставленных бюджетных и заемных финансовых ресурсов и не должен превышать $30 \%$ от стоимости инвестиционного проекта;

- ставка рефинансирования ЦБ РФ не должна быть меньше коммерческой банковской ставки более чем на $10 \%$;

- период реализации инвестиционного проекта не должен превышать 10 лет.

Pезультаты и обсуждение / Results and discussion. По отобранным проектам в соответствии с предоставленными данными были рассчитаны прибыль проектов, стоимость их инфраструктурной поддержки, а также необходимый объем субсидий и налоговых льгот (таблица 1).

Таблича 1

Финансово-экономические показатели инвестиционных проектов, реализуемых в рамках ГЧП, млн руб.

\begin{tabular}{|c|c|c|c|c|c|}
\hline № проекта & Приб̆ыль & $\begin{array}{c}\text { Объем } \\
\text { инвестиций }\end{array}$ & $\begin{array}{c}\text { Размер } \\
\text { инфраструктурной } \\
\text { поддержки }\end{array}$ & Субсидии & Налоговые льготы \\
\hline 1 & 5931,00 & 4544,83 & 888,63 & 66,26 & 100,30 \\
\hline 2 & 1877,64 & 1169,87 & 402,37 & 5,87 & 25,82 \\
\hline 3 & 17421,20 & 12311,80 & 967,20 & 14,10 & 271,71 \\
\hline 4 & 9934,64 & 5355,60 & 1429,70 & 20,84 & 118,19 \\
\hline 5 & 1555,89 & 1115,33 & 217,86 & 3,18 & 24,61 \\
\hline 6 & 4740,44 & 3604,90 & 3473,09 & 50,64 & 79,56 \\
\hline 7 & 1532,18 & 883,10 & 844,54 & 12,31 & 19,49 \\
\hline
\end{tabular}

Целесообразность софинансирования отобранных инвестиционных проектов для последующей их реализации в рамках ГЧП была рассмотрена для трех базовых вариантов:

- в 1-м варианте государство берет на себя обязательства по инфраструктурному обеспечению реализации инвестиционного проекта, например, строительства коммунальных сетей и подключения к ним частных инвесторов. В данном случае предоставление субсидий и налоговых льгот не предусмотрено;

- 2-й вариант, который подразумевает совместное софинансирование расходов на инфраструктуру со стороны государства и частного инвестора в пропорции $75 \%$ и $25 \%$ соответственно, при этом налоговые льготы и субсидии предоставляются в полном объеме;

- 3-й вариант аналогичен второму за исключением перераспределения затрат в пропорции $50 \%$ на $50 \%$ (таблица 2). 
Результаты расчетов бюджетной и финансовой эффективности

\begin{tabular}{|c|c|c|c|c|c|c|}
\hline \multirow{2}{*}{$\begin{array}{c}\text { № } \\
\text { проекта }\end{array}$} & \multicolumn{2}{|c|}{ 1-й вариант } & \multicolumn{2}{|c|}{ 2-й вариант } & \multicolumn{2}{|c|}{ 3-й вариант } \\
\hline & Б3 & $\Phi^{\prime}$ & 6Э & ФЭ & БЭ & $\Phi \ni$ \\
\hline 1 & 1,335 & 1,044 & 1,057 & 1,057 & 1,767 & 1,242 \\
\hline 2 & 0,933 & 1,284 & 0,805 & 1,256 & 1,130 & 1,164 \\
\hline 3 & 3,348 & 1,052 & 2,042 & 1,096 & 3,129 & 1,312 \\
\hline 4 & 1,390 & 1,484 & 1,158 & 1,478 & 1,387 & 1,203 \\
\hline 5 & 1,428 & 1,116 & 1,127 & 1,130 & 1,759 & 1,242 \\
\hline 6 & 0,393 & 1,516 & 0,368 & 1,298 & 0,449 & 0,920 \\
\hline 7 & 0,363 & 1,388 & 0,339 & 1,190 & 0,456 & 0,922 \\
\hline
\end{tabular}

Как видно, в проектах, планируемых к реализации, где величина расходов, необходимых для развития инфраструктуры, сопоставима со стоимостью инвестиционных проектов (проекты 6 и 7), ожидаемо наблюдается максимально низкий уровень эффективности по бюджетному критерию. Если расходы распределить в соответствии с 3-м вариантом, то это приведет к снижению критерия финансовой эффективности до 0,92 по первому проекту и 0,922 по второму проекту, что снижает уровень их инвестиционной привлекательности даже с учетом предоставляемых льгот и субсидий.

В проектах, где затраты на инфраструктуру в общей структуре инвестиций не превышают $30 \%$ (проекты 1-5) наблюдается положительный эффект от реализации 2-го и 3-го вариантов реализации проектов в рамках ГЧП. Как следствие, перераспределение расходов, связанных с развитием инфраструктуры от бюджетных расходов к частным инвестициям требует дополнительных затрат государства в виде предоставления субсидий и налоговых льгот, что не только приведет к дополнительной заинтересованности частного бизнеса за счет роста показателя финансовой эффективности, но и повысит бюджетную эффективность.

Таким образом, первоначальные технико-экономические показатели инвестиционного проекта, а именно структура затрат в разрезе инфраструктурной и производственной составляющей, играют главную роль при принятии решения как со стороны органов государственной власти, так и бизнеса в его реализации в рамках ГЧП. Чем ниже доля вложений на развитие инфраструктуры, тем более привлекательным является проект для инвесторов проектов. В таких проектах особую роль играют меры государственной поддержки, которые предоставляются в рамках ГЧП, при этом как субсидии, так и налоговые льготы оказывают практически одинаковый положительный эффект.

Заключение / Conclusion. Как показали результаты проведенного исследования, современное состояние национального промышленного комплекса, которое характеризуется высоким уровнем износа основных фондов и их моральным устареванием, является одной из основных причин снижения уровня экономической безопасности территориально-отраслевых комплексов. Рост инвестиционной активности предприятий промышленности позволяет отчасти решить данную проблему, однако длительный инвестиционный цикл и масштабность инвестиционных проектов, реализуемых в промышленности, выступают естественными ограничителями для их реализации.

В этой связи особая роль в стимулировании инвестиционной активности отводится государству на основе использования механизма государственно-частного партнерства, который особенно эффективен в мезоуровневых системах. Основной задачей является поиск оптимальной схемы отбора и реализации крупномасштабных инвестиционных проектов. 
Результаты экономико-математического моделирования показали, что простое увеличение удельного веса прямого участия государства за счет прямого финансирования проекта в рамках ГЧП за счет инфраструктурных инвестиций или косвенное - за счет предоставления налоговых льгот не всегда способсттует росту инвестиционной привлекательности проекта для частного инвестора. Для случая, когда доля инфраструктурных инвестиций превышает 50 \%, точка равновесия отсутствует, а интервал равновесных значений индексов бюджетной и финансовой эффективности превышает установленные границы, что делает нецелесообразным участие государства в его реализации в рамках ГЧП.

\section{ЛИТЕРАТУРА И ИНТЕРНЕТ-РЕСУРСЫ}

1. Борталевич С. И., Акопова А. В. Особенности стратегического управления модернизацией российской промышленности // Транспортное дело в России. 2016. № 1. С. 94-96.

2. Варнавский В. Г. Партнерство государства и частного сектора: формы. проекты, риски. М.: Наука, 2005. $315 \mathrm{c}$.

3. Воробьева И. М., Пономарев А. М. Оценка эффективности инвестиционных проектов // Молодой ученый. 2015. № 10. С. 563-567.

4. Дохолян С. В. Управление устойчивым развитием территориальных социально-экономических систем мезоуровня // Экономика и предпринимательство. 2011. № 6. С. 14-21.

5. Единая информационная система государственно-частного партнерства в Российской Федерации. URL: http://www.pppi.ru/projects (дата обращения: 19.02.2019).

6. Егорова Н. Е., Ерзнкян Б. А. Методы согласования экономических интересов субъектов государственно-частного партнерства // Теория и практика институциональных преобразований в России. 2016. № 7. C. 7-12.

7. Кабашкин В. А., Сидоров А. Е. Развитие государственно-частного партнерства в регионах Российской Федерации. М.: Изд. дом «Дело». 2003. 120 с.

8. Петросян Д. С., Скрипник О. Б. Методология формирования механизма государственно-общественного регулирования национальной экономики // Аудит и финансовый анализ. 2016. № 6. С. $363-369$.

9. Практическое руководство по вопросам эффективного управления в сфере государственно-частного партнерства / Европейская экономическая комиссия Организации Объединенных Наций: ООН. Нью-Йорк; Женева, 2008. 114 с.

10. Об утверждении методики оценки эффективности проекта государственно-частного партнерства и определения их сравнительного преимущества: Приказ Минэкономразвития РФ от 30.11.2015 № 894 [Электронный ресурс] // Доступ из СПС «КонсультантПлюс».

\section{REFERENCES AND INTERNET RESOURCES}

1. Bortalevich S. I., Akopova A. V. Osobennosti strategicheskogo upravleniya modernizaciej rossijskoj promyshlennosti (Features of strategic management of modernization of the Russian industry) // Transportnoe delo v Rossii. 2016. No 1. S. 94-96.

2. Varnavskij V. G. Partnerstvo gosudarstva i chastnogo sektora: formy. proekty, riski (Partnership between the state and the private sector: forms. projects, risks). M.: Nauka, 2005. $315 \mathrm{~s}$.

3. Vorob'eva I. M., Ponomarev A. M. Ocenka ehffektivnosti investicionnyh proektov (Estimation of efficiency of investment projects) // Molodoj uchenyj. 2015. No 10. S. 563-567.

4. Doholyan S. V. Upravlenie ustojchivym razvitiem territorial'nyh social'no-ehkonomicheskih sistem mezourovnya (Management of sustainable development of territorial socio-economic systems of mesolevel) // EHkonomika i predprinimatel'stvo. 2011. No 6. S. 14-21.

5. Edinaya informacionnaya sistema gosudarstvenno-chastnogo partnerstva v Rossijskoj Federacii (Unified information system of public-private partnership in the Russian Federation). URL: http://www.pppi.ru/ projects (data obrashcheniya: 19.02.2019).

6. Egorova N. E., Erznkyan B. A. Metody soglasovaniya ehkonomicheskih interesov sub"ektov gosudarstvennochastnogo partnerstva(Methods of coordination of economic interests of subjects of public-private partnership)// Teoriya i praktika institucional'nyh preobrazovanij v Rossii. 2016. No 7. S. 7-12. 
7. Kabashkin V. A., Sidorov A. E. Razvitie gosudarstvenno-chastnogo partnerstva v regionah Rossijskoj Federacii (the Development of public-private partnership in the regions of the Russian Federation). M. Izd. dom «Delo», 2003. $120 \mathrm{~s}$.

8. Petrosyan D. S., Skripnik O. B. Metodologiya formirovaniya mekhanizma gosudarstvennoobshchestvennogo regulirovaniya nacional'noj ehkonomiki (Methodology of formation of the mechanism of state and public regulation of the national economy) // Audit i finansovyj analiz. 2016. № 6. S. 363-369.

9. Prakticheskoe rukovodstvo po voprosam ehffektivnogo upravleniya $v$ sfere gosudarstvenno-chastnogo partnerstva (A practical guide to promoting good governance in public-private partnerships). Evropejskaya ehkonomicheskaya komissiya Organizacii Ob"edinennyh Nacij: OON. N'yu-Jork; ZHeneva, 2008, $114 \mathrm{s.}$

10. Ob utverzhdenii metodiki ocenki ehffektivnosti proekta gosudarstvenno-chastnogo partnerstva i opredeleniya ih sravnitel'nogo preimushchestva (On approval of the methodology for assessing the effectiveness of the project of public-private partnership and determining their comparative advantage): Prikaz Minehkonomrazvitiya RF ot 30.11.2015 No 894 [EHlektronnyj resurs] // Dostup iz SPS «Konsul'tantPlyus».

\section{СВЕДЕНИЯ ОБ АВТОРАХ}

Руденко Владимир Валентинович, кандидат экономических наук, доцент кафедры экономики Ставропольского института кооперации (филиал) Автономной некоммерческой организации высшего образования «Белгородский университет кооперации, экономики и права», г. Ставрополь. E-mail: v89283500000@gmail.com

Ниров Петр Николаевич, аспирант кафедры экономической безопасности ФГБОУ ВО «Кубанский государственный технологический университет», г. Краснодар. E-mail: pnshir@mail.ru

\section{INFORMATION ABOUT AUTHORS}

Vladimir Rudenko, Candidate of Economic Sciences, assistant Professor at the department of economics of Stavropol Institute of Cooperation (branch), Belgorod University of Cooperation, Economics and Law, Stavropol. E-mail: v89283500000@gmail.com

Petr Shirov, post-graduate student of the Department of economic security of Kuban state technological University, Krasnodar. E-mail: pnshir@mail.ru 